\title{
Technology Management: Corporate-Startup Co-Location and How to Measure the Effects
}

\begin{abstract}
Annika Steiber*
Abstract: Rapid technological developments make firms favor the creation of new approaches to technology management. Startups can offer large firms access to new technologies and the emphasis on corporate-startup collaboration has therefore reached a new level. Many models exist and colocation is one of these. While co-location in the context of clusters and innovation systems has been studied in previous literature, research on corporate-startup co-location is limited. The purpose of this paper is to investigate the broader phenomenon of business co-location and based on this review, suggest a framework and metrics to evaluate the effects of corporate-startup co-location. The paper originates from earlier conducted studies on corporate-startup collaboration models. For this paper a literature review on the broader phenomenon of business co-location is conducted. The theoretical contribution is a proposed multi-stakeholder framework and metrics for evaluating the effects of corporate-startup co-location.
\end{abstract}

Keywords: Co-location, startup; framework; metric; open innovation.

Submitted: May $4^{\text {th }}, 2020 /$ Approved: July $24^{\text {th }}, 2020$

\section{Introduction}

Rapid technological development and knowledge production, create a tremendous pressure on incumbents to radically change the way they are organizing their innovation processes, if they at all will have a chance of surviving and prospering (March, 1991; Christensen and Overdorf, 2000; Lee et al., 2012; Badescu and Garcés-Ayerbee, 2009; Trabucchi et al., 2017), and many companies have conducted different initiatives to explore new technologies, and to exploit their benefits (Matt et al., 2015; Hess et al., 2016).

This also drives the creation and diffusion of new types of entrepreneurship (Oukil, 2011), affecting large firms to change their approach to technology management. Therefore, as a complement or alternative to internal $\mathrm{R} \& \mathrm{D}$, high technology strategic alliances offer large firms access to technologies (Powers and Wilson, 2010; Aggarwal \& Kapoor, 2018; Clauss and Spieth, 2017; Kilubi, 2016; Roth et al., 2017). Corporate-startup collaboration, as one form of high technology strategic alliances, is increasingly becoming an attractive strategy (Weiblen and Chesbrough, 2015; Steiber and Alänge, 2020). For this reason, many different models have been developed and applied by large firms (Steiber and Alänge, 2020). Corporate-startup co-location is one of those models that increasingly gets traction among large corporations, as well as from startups and local Governments (Steiber and Alänge, 2020). While co-location in a context of clusters, ecosystems, and innovation systems has been studied in previous research, large firms' initiatives of co-locating startups close to the large firm's vicinity, is a phenomenon that is limited researched.

In this paper 'corporate-startup co-location' is viewed as a management initiative of the placement of several tech startups in a single location often close to the large firm's vicinity. Typical the large firm has created a lab or workspace for small tech firms ("the corporate version of the Maker Movement"). The idea behind co-locating small tech firms is to have startups to benefit from access to the larger firms' competencies and resources, while the larger firms develop relationships that could provide useful innovation inputs (Remneland Wikhamn and Styhre, 2017). Co-location is a non-equity form for corporate-startup collaboration, which could speed up innovation for the corporation by e.g. provide a rather inexpensive way to take part of the construction of totally new entrepreneurial ecosystems (Drori and Wright, 2018), and to learn from these ecosystems. For the startups this strategic avenue is also of interest as it could be a way for them to overcome innovation diffusion challenges (Autio et al. 2018) without giving up equity. As a result, both local corporations and startups seem to win on the co-location, why the local Government, in the interest of the country or region, also commonly fund those initiatives.

However, our knowledge in general of non-equity forms for collaboration, such as e.g. corporate-startup co-creation and co-location, is not enough developed (Frow et al. 2015; Steiber and Alänge, 2020). In particular, research on how to evaluate and measure the results from both corporate-startup co-creation and co-location is more or less non-existent (Steiber and Alänge, 2020).

The purpose of this paper is to investigate the broader phenomenon of business co-location and based on this review, suggest a framework and metrics to evaluate the effects of corporate-startup co-location.

The theoretical contribution is a proposed multi-stakeholder framework and metrics for evaluating the effects of corporate-startup co-location.

The sections below start with theoretical context and methodology, followed by result from the management literature review on existing research on business co-location. Finally, the results from the new literature review are presented, as well as conclusions and implications.

*Menlo College, Atherton, CA 94027, USA.

Email: annika.steiber@menlo.edu 


\section{Theoretical Context}

Digital technologies have increased the uncertainty inherent in entrepreneurial processes and outcomes, which has led to less bounded entrepreneurial processes and outcomes, and less predefined locus of entrepreneurial agency (Nambisan, 2017). Corporate-startup collaboration efforts allow new approaches for technology management and allow the large firm to access, or even build new ecosystems for increased innovation (Drori and Wright, 2018). As a result, this type of collaboration for technological innovation seems to be on an increase:

"During the last few years...corporate efforts to reach out to the startup ecosystem seem to be on the increase. In its quest for speed and innovation, the tech industry, in particular has produced a variety of ways of engaging with startups." (Weiblen and Chesborough (2015, p. 67).

Chesbrough (2003) developed the open innovation concept from observations of inbound and outbound streams of technology at large firms. The fast technology development in most industries is now increasing the emphasis on startups' role in corporate innovation, as the strength of small technology startups is their ability to develop not only new product and process innovations rapidly and test them on 'early adopers' (Rogers, 1995), but also to develop entirely new business models. For large firms, technology startups can also allow the large firm to be part of the construction of totally new entrepreneurial ecosystems that otherwise may not be available for the large firms. The main weakness with startups is their limited ability to scale up for high-volume operations (Autio et al. 2018). Large firms typically show the opposite areas of strengths and weaknesses. This has led some authors to suggest cooperation in which the large and the small firm play interactive and complementary roles (Rothwell and Dodgson 1991; Prashantham and Birkinshaw 2008).

\section{Models for corporate-startup collaboration}

Previous research has identified several different models for corporate-startup collaboration that could be positioned along two main dimensions; the direction of the innovation flow (outside-in or insideout) and equity-based versus non-equity-based model (Weiblen and Chesbrough, 2015; Steiber and Alänge, 2020).

Models using an inside-out flow as well as an equity-based model are: Internal Corporate Incubator, and Internal Corporate Accelerator. As large firms have realized the need for rapid learning, e.g. through the work of Steve Blank and Eric Ries (Blank 2005; Ries 2011), this has influenced the design of the two models: internal corporate incubator, where internal ideas may lead to spinout companies, which put internal assets to use and can also potentially be reacquired later, and internal accelerator programs, an intensive, shorter program in which cohorts of (here internal) idea providers are coached to take their ideas further (Hochberg, 2016).

Acquisition and Corporate Venturing are models using an outside-in flow as well as an equity-based model. Acquisition, in which the large firm acquires the startup, is a common way of obtaining assets deve- loped elsewhere - including technology, talent, competencies, and/ or patent portfolios. Corporate- venturing, is when the firm invest in external startups of strategic interest. Acquisitions and corporate venturing are the oldest models of the eight. Venture activities first appeared in the early 1900s - Du Pont's investment in the startup Ford in 1914 is an early example (Siota et al., 2020) - and has mirrored the industry as a whole (Gompers and Lerner, 2000).

Models using an inside-out flow as well as a non-equity-based model are, platforms and corporate startup programs. By platforms it is meant a large firm's proprietary platform, e.g., Android or iOS. The 'Platform model' is an Inside-out approach in which the larger firm invites complementary external startup innovation to advance existing corporate innovation (the platform), but also to strengthen the large firm's ecosystem. The primary purpose of setting up a Corporate Startup Program such as e.g. Google for Startups, is for the large firm to support entrepreneurs with access to the large firm's products, services, or other assets and thereby sustaining or even expanding the ecosystem around the large firm's products and services. The 'platform' and the 'corporate startup program' are both examples on nonequity collaboration models and are rather new concepts. For example, NTT DoCoMo's i-mode platform was launched in 1999 and both Apple App Store and Google's Android platform were launched in 2008. Google for Startups was launched as Google for Entrepreneurs in 2011.

Finally, co-creation and co-location are models using an outside-in and non-equity-based model. Co-creation is a management initiative, or form of economic strategy, that brings different parties together (for instance, a company and a group of customers), in order to jointly produce a mutually valued outcome (Normann \& Ramirez, 1994; Wikström, 1996; Prahalad and Ramaswamy, 2004). Business co-location is the placement of several entities in a single location. In the context of co-location of tech startups close to a host corporation, co-location is a rather new phenomenon. Co-location initiatives for startups commonly offer co-working space for a low rent, some business services, but also in several cases access to the large firm's equipment and lead researchers. As can be noticed, there is an important difference between these concepts. While co-creation is explicitly focused on bringing external innovation in-bound, co-location can be the placement of startups in a single location in the vicinity of the large firm with either a clear focus on contributing to a specific identified product area of the corporate or to a more general purpose of preparing for collaboration opportunities through serendipity.

Earlier research on corporate-startup collaboration models has shown that there is very limited research on the specific model; corporatestartup co-location (Steiber and Alänge, 2020). Further, research on how to measure and evaluate this model's results is more or less nonexistent (Steiber and Alänge, 2020).

\section{Methodology}

In order to extend the existing knowledge on this phenomenon as such, and on frameworks and metrics that could be used for evaluating this kind of corporate-startup model, a broader literature study on business 
co-location was conducted for this paper. The literature review was conducted following the methodological guidelines of Webster and Watson (2002). Academic literature matching selected search strings were searched for in the databases; EBSCO and Business Source Complete, $\mathrm{ABI}$ Proquest and Proquest Dissertations and thesis, JSTOR and $\mathrm{Bu}-$ siness, ScienceDirect, as well as Google Scholars. The databases were selected as they index most significant journals and conferences, as well as dissertations in the management domain. As a first step, titles and abstracts were manually screened. Articles rated A by the authors were literature reviews on the phenomenon of 'business co-location'. Articles focused on 'business co-location' in a specific theoretical context (e.g. cluster or ecosystem), were classified as B articles. Finally, articles not directly relevant to the purpose of this paper were excluded.
Business co-location as a studied phenomenon was found in previous research in contexts such as; 'cluster theories', 'ecosystem theories, network theories', theories on knowledge dissemination, as well as on corporate coworking (spaces).

In total (60) abstracts from A and B rated scientific articles were selected. After a more thorough scanning of the 60 articles, 32 articles were finally selected and read to provide a better understanding of business co-location from five different perspectives (see Table 1 and literature stream). For more details about the 32 selected papers, please see the table below.

Table 1. Selected articles, based on the literature review






\section{Discussion of Results}

In this paper corporate-startup co-location is viewed as one model for applying outside-in open innovation, which in turn is a rather new paradigm for manage technology of any large firm. However, already Teece (1986), explored why innovating firms often fail to obtain significant returns from an innovation and found that the innovating firm in some cases needs to establish a prior position in complementary assets, in addition to be the developer of the intellectual property. This could mean that the firm needs to form alliances or some sort of networking with external partners that are owners of complementary assets to the firm. The total value created in those alliances or networks depends directly on how well partners' objectives are aligned to each other and on the commitment of the partners to invest in complementary assets (Teece, 1986). Chesbrough and Rosenbloom (2002) consider the value network as a function of the business model, in which the business model pinpointing the position a firm takes within the value network linking suppliers, customers, complementors and competitors (Vanhaverbeke, 2005). The value network shapes thereby each party's role in capturing value from the commercialization of an innovation. The network partners can play one or two important roles for the large firm. Either they play a role in resource allocation of technologies, or they play a role in supporting the commercialization of more radical, but also incremental innovations (e.g. improved existing products). In regard to resource allocation the innovating company has to manage other actors in the network in a proactive way through foresight and shaping. In regard to speed up the commercialization of new radical innovations, the different partners in the network that own complementary assets need to make investments that are support this commercialization (Vanhaverbeke, 2005). These firms, in turn will only join if those investments will be profitable. In the case of systemic innovation, innovating companies are even more dependent on complementary innovators forcing them to take an external perspective to resource allocation processes (Vanhaverbeke, 2005). Previous research on a dyad level has studied the art of alliances, alliance formation, alliance advantages, and alliance management (Bamford and Ernst, 2002; Vanhaverbeke, 2005). How to create and capture value in a network, where companies are highly dependent on each other, is however, still an under-explored area in the network literature (Vanhaverbeke, 2005).

The literature review conducted for this paper on the phenomenon 'co-location' shows that business co-location has been studied in previous research. Even if economic theories indirectly or directly has discussed the phenomenon, the concept has most explicitly been studied from a context of cluster theories (Cooke, 2002; McKelvey et al., 2003; Stuart and Sorenson, 2003; Yeung et al., 2006; Porter et al., 2006; Robinson et al., 2007), Ecosystems/ Network theories (Lemarie'et al., 2001; Gertler and Levitte, 2005; Vanhaverbeke, 2005; Gallivan, 2008; Muegge, 2013; Romero and Molina, 2011; and Valkokari et al., 2017), Learning and Knowledge dissemination (Nonaka, 1994; Inkpen and Tsang, 2005; Simard and West, 2005; Song et al., 2007; Zenun et al., 2007; Chow and Chan, 2008; and Holste and Fields, 2010) and Corporate co-working/collaboration spaces (Bouncken et al., 2016; Ca- bral and van Winden, 2016; Cabral and van Winden, 2018; Nagy and Lindsay, 2018; Irving et al., 2019). Below, some interesting findings will be presented from these streams of research.

\section{Cluster theories}

Open innovation benefits could be expected to be more readily achieved in regional clusters as the effect of networks on innovation is magnified by geographic proximity (Simard and West, 2005). Also, economists have pointed out the benefits of localization on economic growth (Stuart and Sorenson, 2003; Simard and West, 2005) such as reduced production and transportation costs and lower costs of accessing information locally. In fact, startups in high- technology and in biotechnology have long realized that co-location enables them to tap into necessary knowledge. In the last decades we find a similar trend among larger firms that start research labs in different innovation hubs around the world.

Earlier research on biotechnology clusters in Germany, Cambridge, Massachusetts, and Cambridge, U.K. shows that: "biotechnology...like many other new economy industries such as information and communication technology, new media, and advanced finance, firms cluster in proximity to knowledge sources" (Cooke, 2002, p: 8). Clusters offer key competitive advantages over vertical integration in single firms, such as productivity (lower transaction costs and untraded interdependencies), innovation (through interactive knowledge exchange), and new business formation (assisted by mentoring, role modelling, learning, and commercialization gains) (Cooke, 2002, pp. 9-10). The lower transaction costs could be supported by findings in transaction- based theories. According to Teece (1986a) transaction cost economics provides a framework for discriminating between those transactions which needs to be internalized and those which do not. According to this theory, the decision will depend on in what situation the transaction costs is the lowest for the firm. In a situation of systemic innovation and an increasing complexity for the firm, colocate startups to the vicinity of the large company could lower the transaction costs for the large firm in accessing new technologies. This should specifically be true in the case of 'wide' ties. According to Vanhaverbeke (2005), it is relevant to differ between deep and wide ties. The deep ties, according to the author enables a company to capitalize on existing knowledge and resources (exploitation and more incremental innovations). The wide ties therefore offer opportunities for a firm to explore new technologies if those ties span structural holes and link the firm to diverse technological environments. Vanhaverbeke (2005) also differ between formal and informal ties. Formal ties, in contrast to informal ones, are those based on contracts and are 'planned' channels for knowledge. Informal ties are harder to manage and make it more difficult to control the knowledge flows in and out of the firm. The transaction costs for any large firm to internally manage wide and informal ties, could therefore be assumed to be higher why the large firm is more prone to manage those ties outside of the form, e.g. in a co-location setting. However, also for the small firms, transaction costs need to be lower as investment is tight (Cooke, 2002). In fact, 'strength-in-numbers' characterizes the practices of the small-firm ecosystem defining the originators of new innovation (Cooke, 2002). The transaction costs for small firms 
can be lower, or even removed by trustful exchange, reputational trading and collective learning in localized knowledge networks (Cooke, 2002). In addition, Yeung et al. (2006) state that the existing literature has underestimated the role of external economies of collective bargaining and production capacity accruing to firms in clusters that are derived from traded relationships with institutions, firms, and customers outside local clusters. They define these benefits as non-cluster economies of traded interdependencies among firms in clusters. Meanwhile, prospects of long- term profit continue to attract complementary businesses into the cluster.

McKelvey et al. (2003), Porter et al. (2006), and Robinson et al. (2007) all assessed the validity of assumptions about the importance of colocation for innovation by analyzing whether or not co-location matters for formal knowledge collaboration (defined as co-development, co-authorship, or collaborative R\&D) in the Swedish biotechnologypharmaceutical sector. According to the authors, within the systems of innovation literature, innovation is argued to result from a collective process of knowledge development. Further, according to the authors two assumptions underlie the majority of innovation systems analyses:

- that interactions occur among the chosen population of actors

- that these interactions influence innovations, and thereby economic growth

However, metrics on how to measure these inter-organizational knowledge flows is a challenge. Citing patents of partners, licensee agreements and royalty payments measure some form of knowledge in formal ties, but new measures are needed to manage informal ties (Vanhaverbeke, 2005). By collecting data on the frequency of certain deals among the population of biotechnology-pharmaceutical firms they found that the most frequent types of agreement (formal ties) between January 1993 and May 2000 were 'co-development of technology' (48) and 'licensing agreements' (33). Acquisition of technology and clinical testing and contract research had only a frequency of 11 and 8 during the same time period. Results from informal ties were not measured but is known by researchers to lead to recognized but unexpected knowledge spillovers (Simard and West, 2005).

\section{Ecosystem and Network theories}

Romero and Molina (2011) as well as Muegge (2013) investigated how value was co-created in business ecosystems. Both found that this new 'set-up' between a corporation and external partners was an important driver for co-innovation. Further, from a business ecosystem perspective, research from Valkokari et al. (2017) show some interesting results. Their focus was on orchestrating innovation ecosystems and how larger firms, as well as startups position themselves in those ecosystems. They found that a key success factor is 'ecosystem competence', and the ability to manage dynamic strategic interactions related to innovation. This in turn is built on trust as a coordination mechanism (Gallivan, 2008). Trust is crucial in reducing the risks associated with interfirm relations but could in the same time be damaged due to each firm's aim to learn as much as possible from the other (Simard and West, 2005). Also Chow and Chan (2008) studied the importance of trust in organizational knowledge sharing. They confirmed that a social network and shared goals significantly contributed to a person's willingness to share knowledge, and directly contributed to the perceived social pressure of the organization. Social trust showed an indirect effect on the attitude and subjective norm of sharing knowledge. Finally, Valkokari et al. (2017) found that established firms, however commonly focused on orchestrating the existing business ecosystem, while startups more typically saw their role in composing future ecosystems.

From a network perspective, networks are especially well suited to knowledge-intensive industries where joint problem solving is important (Simard and West, 2005). One important aspect of networks is the separation of local versus global networks. Gertler and Levitte (2005) investigated local nodes in global networks, or how the geography of knowledge flows in biotechnology innovation. The authors claim that the literature on innovation and interactive learning has tended to emphasize the importance of local networks. However, this view has been challenged and new perspectives are arguing for the importance of non-local knowledge flow. Their findings are interesting for this paper as they found that local relational linkages are especially important for the startup when raising capital, and the expertise that comes with it. However, when the startup grow, relevant partners might not be local. In fact, the authors show that in Canada both knowledge flows and capital flows (in the form of payments received from licensing IP) are increasingly extending beyond the immediate locality and nation to foreign partners and sources. This external orientation may of course be a product of both the location and the age of the industry. However, it might indicate that co-location that usually is in the vicinity of the large firm need to embed both a local and global layer of networks. Also, Lemarié et al. (2001) studied the importance for smaller firms with geographic proximity (spatial separation and relations in terms of distance) versus organizational proximity (affiliation, that is actors belonging to the same area of relations, and similitude, that is actors who resemble one another in e.g. knowledge) for fruitful interaction, specifically in regards to tacit knowledge that is hardest to disseminate between parties in any network (Nonaka, 1994). They found that for startups in their very early phases, geographic proximity matters, while later when the firm has developed further, organizational proximity matters more than geographical proximity. Further, they found that the local infrastructure (e.g. access to technological platform or academic research, etc.) plays a key part in firms' localization. As a startup's needs should change while growing, also the local infrastructure might need to change for the startup.

\section{Learning and Knowledge dissemination theories}

Due to the increasing globalization of businesses, new ideas for innovation need to be disseminated rapidly both within and across different departments, divisions, but with open innovation, also between partners in a network. In a context of knowledge dissemination, it is important to separate information from knowledge. Information is a flow of messages, while knowledge is created and organized by the flow of information, based on the current knowledge of its holder (Nonaka, 1994). Knowledge in turn is commonly divided into tacit 
knowledge and explicit knowledge (Chow and Chan, 2008). As tacit knowledge is harder to imitate it commonly has greater competitive value (Simard and West, 2005; Song et al., 2007; Holste and Fields, 2010). Desirable and undesirable knowledge flows is through people and their interactions (Inkpen and Tsang, 2005), particularly for tacit knowledge and as Chesbrough (2003) state, most new knowledge is originated outside of the firm. Teece (1989) found that cooperation between firms increases knowledge gain and networks therefore have been found to benefit returns on innovation such as rate of patents, improvement of existing products, new product development, faster time to market, and access to new markets (Simard and West, 2005). The fact that location matters for new knowledge creation was also found by Porter et al., (2006) that studied the biotechnology industry. Also, research on knowledge dissemination in technology development processes within high-technology firms found that co-location of R\&D staff matters. Due to different types of knowledge, they found that effective knowledge dissemination requires a balanced investment in both co-location and information technologies to be able to deal with the heterogeneous but interdependent types of knowledge dissemination. and Song et al. (2007) investigated the importance of co-locate IT resources, while Zenun et al. (2007) investigated the effects of product development teams' co-location on project performance. Both found that the co-located teams appeared to deliver better performance at least on the efficiency parameters (productivity and lead time). One explanation for this according to the researchers was the increased informal communication between team members in the co-located teams. However, they did not find any support for that colocation impacted quality.

Even if location and interorganizational knowledge flows matter for internal innovation, measuring such flows remains a challenge, independent of if they are used as antecedent, mediator, or outcome of the firm's level of innovation (Simard and West, 2005). One metric used is patent- data but this is an imperfect measure of innovation (Gallini, 2002). Ideally, both technological innovations (patents) and commercialization of that innovation should be measured, e.g. annual licensing revenues, new product development, and market share of new products (Simard and West, 2005). However, these metrics measures knowledge utilization across formal ties, not informal ties whose results are much harder to measure.

\section{Theories on Collaborative work-spaces and Co-working spaces}

One form of co-location of entrepreneurs and employees in corporates are collaborative workspaces that initially became popular as independent units - but later on were started by large incumbents as corporate coworking spaces. The purpose of these spaces can vary considerably and according to Nagy and Lindsay (2018) the purposes typically fall into one or more of three groups: Transformation, Innovation and Future proofing. If the space aims for Transformation of the corporate it is designed to impact the culture, why employees (e.g. R\&D people) are offered experiences to test and learn how startups thinks and work. If Innovation is the goal, then diverse stakeholders such as startups or university researchers are assembled to solve a specific task and they are equipped with facilities and methodologies from the large firm. This is not only to drive innovation but could also be a way for the large firm to 'educate' external people in competences and skills that the large firm needs to recruit. This would thereby increase their pool of talents for employments. Finally, if the goal is $\mathrm{Fu}$ ture proofing, it is more open ended, and the space is designed to generate new contacts or ideas. This could happen through e.g. seminars and conferences at the co-location arena, but also by having the large firm's R\&D personnel to meet with external partners through a more or less serendipity approach. Nagy and Lindsay (2018) comment that the spaces seem to be promoting innovation, but it is difficult to measure their effectiveness and only quantifiable indirectly, through user interviews and satisfaction surveys, e.g. approval rating of the space. Demonstrating ROI is difficult and according to Nagy and Lindsay (2018): "some eschew metrics altogether, gambling that they will learn as they go when it comes to measuring what's important. Many prefer the soft metrics, such as satisfaction and engagement ... and still others defer measurement into the future, minimizing expenses while awaiting a business case to emerge." For this reason, Nagy and Lindsay emphasize that strong executive sponsors are crucial for corporate coworking - and they provide examples of top- level executives personal involvement in the corporate coworking spaces of SAP and Orange, two of the pioneering companies.

Similar research to Nagy and Lindsay (2018) is the research by Cabral and van Winden (2016). Cabral and van Winden (2018), choose to study four categories of collaborative workspaces; accelerators, incubators, coworking spaces and FabLabs. As both accelerators and incubators provide programs or a set up to support the startup to scale, which is not the case of corporate-startup co-location as defined in this paper, coworking spaces and FabLabs are the two categories most relevant for this paper. Coworking spaces offer both office facilities as well as extra services such as access to on and offline communities, workshops, and networking events. Fablabs (fabrication laboratories but sometimes also named as makerspace, hackspace) are, according to the authors small- scale open workspaces offering (personal) fabrication. Of interest for this paper is that, while coworking spaces primarily offer 'making connection to new people', FabLabs offer primarily 'learning and knowledge sharing'. As could be seen the end goal of these two spaces is very different. Further, according to the authors, coworking spaces focus on serendipity and internal community management, while FabLabs focus on organized facilitation and both external and internal community management (p:22). For both approaches, a balanced mix of coworking benefits and generic business development are benefits and effects from those two collaborative workspaces. Finally, research by both Bouncken et al. (2016) and Irving et al. (2019) emphasize co-working as a new business model design that enables serendipitous encounters.

In summary, previous research on co-location in the context of clusters, ecosystems/networks or collaborative workspaces have identified benefits of co-locating firms and organizations to a specific geographical area. The main benefit and strategic value seem to be knowledge transfer and learning for all involved parties through 'making contacts with new people' and to learn and share knowledge, specifically in a context of systemic innovation with an increased complexity. There are also benefits such as lower transaction costs and an 
increased collaborative negotiation power through 'the-strength-of many', productivity increases, increased innovation, new firm formation, and the potential for the large firm to start a cultural transformation, but also 'educate' external people in their products and processes and thereby increase the pool of talents.

We have, however also seen that geographical proximity might be more important for early startup, while later stage startups benefit more on organizational proximity and global networks. The local infrastructure matters for co-location, but the specific needs might also shift for e.g. a startup while growing.

It has also become clearer that there is a need to separate formal ties from informal, and deep ties from wide. The probability to find metrics to measure real results is higher for formal and deeper ties, while wide and informal ties more or less currently lack metrics. However, these ties are the ones that could be of more importance for the large firm's innovation as those ties provide knowledge into new areas and to more tacit knowledge and spillover effects. Even if metrics for these informal and wide ties are lacking today, many large firms' have established some form of co-location space for external partners. This could indicate that these firms act on a strong 'belief' in the value and necessity of those more informal and wide ties, even if they don't measure the effects through hard KPIs. Below, the selected articles generated from the new literature review are presented.

\section{Proposed Multi-Stakeholder Framework\&Metrics}

With the purpose of identifying a framework and metrics for measuring and evaluating the results of using the model, 'corporate-startup co-location', a broader review of the phenomenon of 'business colocation' in the management literature was conducted.

Through the broadened search for literature under the heading of 'business co-location', we identified a number of articles that provided insights on business co-location in the form of underlying objectives with co-location initiatives, results observed, as well as factors that could affect those results.

A further analysis conducted by the authors led to the conclusion that a three- dimension framework, developed within a broader project on corporate-startup collaboration models, could be applied also in the case of corporate-startup co-location (see Figure 1).
Figure 1. Three dimensions for measuring the results from corporate-startup co-location (Steiber et al. 2020a)

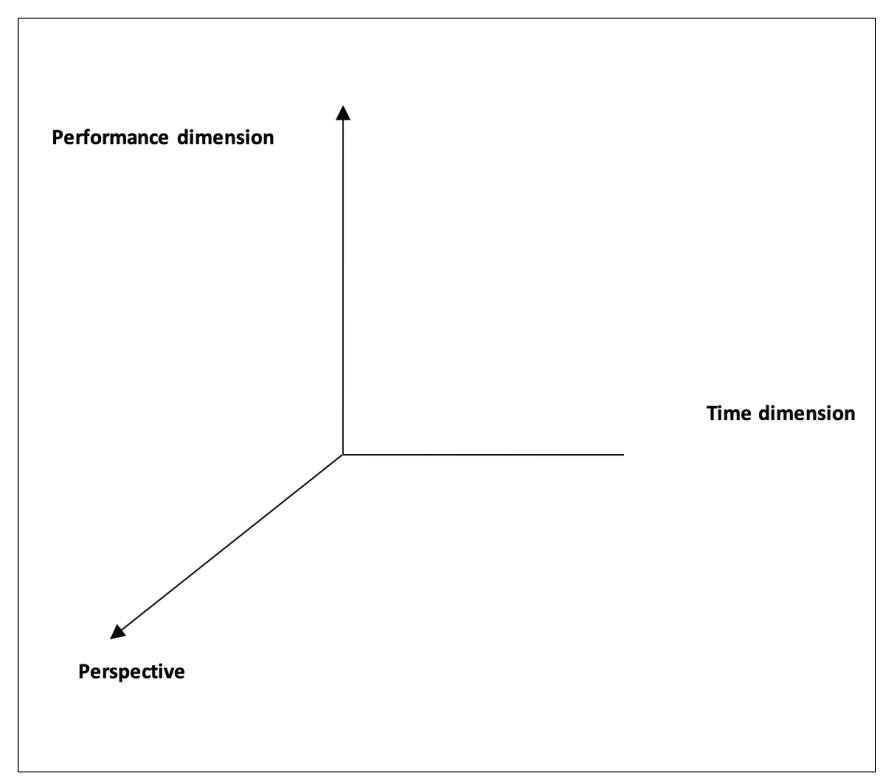

First of all, it is important to consider which perspective/actor is evaluating the results of the co-location initiative (see Table 2 below). The overall objectives are different for corporations, startups, the director of the co-location organization, and e.g. the government (with a national/regional ecosystem perspective as well as state/national or EU-regulations to follow). Several of the studies underline that these stakeholders have different, not always converging goals. It is important, then to be aware of the possible individual goals of each stakeholder, and to measure the associated results in order to take advantage of the synergies, or mediate potential conflicts.

The second dimension concerns the nature of the performance measure considered. The metrics dependent on the actor and their objectives, but also on what type of agreements (formal or informal) that are in place. In the case of more formal agreements, a more planned outcome and result is expected, compared to cases where informal agreements are used. 
Table 2. Different performance areas viewed from a stakeholder perspective (Steiber et al. 2020a)

\begin{tabular}{|c|c|c|c|c|}
\hline & Corporate & Startup & Dyad (Co-Location Org.) & Government \\
\hline Knowledge/Learning & $\begin{array}{l}\text { \# seminars } \\
\text { \# conferences } \\
\text { \# R\&D personnel involved }\end{array}$ & $\begin{array}{l}\text { \# meet ups with experts } \\
\text { \# meet ups with business } \\
\text { professionals } \\
\text { \# connections }\end{array}$ & $\begin{array}{l}\text { \# seminars } \\
\text { \# conferences } \\
\text { \# meet ups }\end{array}$ & $\begin{array}{l}\text { \# of new firms established in } \\
\text { the region }\end{array}$ \\
\hline Productivity & $\begin{array}{l}\text { Decrease in lead time } \\
\text { Decrease in time to market/ } \\
\text { customer } \\
\text { Increase in ROI from R\&D } \\
\text { Increase in sales of own pro- } \\
\text { ducts/processes }\end{array}$ & $\begin{array}{l}\text { Decrease in lead time } \\
\text { Shorter time to market/ } \\
\text { customer }\end{array}$ & $\begin{array}{l}\text { \# external partners engaged/week } \\
\text { \# projects/week } \\
\text { Decreased innovation/BD costs for } \\
\text { any partner }\end{array}$ & $\begin{array}{l}\text { \# local startups engaged in } \\
\text { the co-location initiative }\end{array}$ \\
\hline Innovation & $\begin{array}{l}\text { \# Acquisitions } \\
\text { \# Licensing agreements } \\
\text { \# co-development projects } \\
\text { \# tested new products/processes }\end{array}$ & $\begin{array}{l}\text { \# of new innovation ideas } \\
\text { \# licensing agreements } \\
\text { \# co-development projects }\end{array}$ & $\begin{array}{l}\text { \# co-development projects } \\
\text { \# licensing agreements } \\
\text { \# Acquisitions }\end{array}$ & $\begin{array}{l}\text { \# of industry cross-over } \\
\text { engagements } \\
\text { \# patents generated } \\
\text { \# co-written scientific papers }\end{array}$ \\
\hline
\end{tabular}

The third and last dimension is the temporal one, the time frame (see Table 3). As co-location initiatives are commonly partly funded by the local government, and partly funded by the corporation, both government and the corporation have objectives and requirements on the co-location initiative. Government's objectives and requirements are explicit in the contract that the corporation needs to agree to in order to get funding. In addition to these, the corporation might have their own objectives and then each startup has their own objectives why joining the co-location space. As the co-location initiative is an investment for all three parties (four if to include the co-location space in itself), it is important to track the progress through metrics on a stakeholder level.

Table 3. A stakeholder perspective on metrics, viewed from a time dimension (Steiber et al. 2020a)

\begin{tabular}{|c|c|c|c|}
\hline & Ex-ante & In itinere & Ex-post \\
\hline Corporate & $\begin{array}{l}\text { \# connected startups } \\
\mathrm{X} \% \text { improvement in ROI for R\&D } \\
\text { Y\% improvement on product development } \\
\text { and go-to-market lead time } \\
\text { \# involved R\&D people in initiative }\end{array}$ & $\begin{array}{l}\text { \# Improvement ideas } \\
\text { \# R\&D people involved in co-location } \\
\text { \# Tested products/processes } \\
\text { Increased pool of qualified talents } \\
\text { \# Sold products/processes to ecosystem players }\end{array}$ & $\begin{array}{l}\text { \# Total sold product/processes to ecosys- } \\
\text { tem players } \\
\text { New ROI of R\&D } \\
\text { New product development and go-to- } \\
\text { market lead time }\end{array}$ \\
\hline Startup & $\begin{array}{l}\text { Time of usage of corporate's equipment } \\
\text { \# connections to customers } \\
\text { V\% decreased costs for e.g. business services } \\
\text { WW\% shorter time to get funded } \\
\text { Z\% increase in brand awareness }\end{array}$ & $\begin{array}{l}\text { \# times use of equipment } \\
\text { \# connected customers annually } \\
\text { \# percentage decreased costs for business services } \\
\text { \# percentage decrease in time to funding } \\
\text { \# percentage increase in brand awareness }\end{array}$ & $\begin{array}{l}\text { Final time of usage of equipment } \\
\text { Final \# of customers connected } \\
\text { Decrease in costs for business services } \\
\text { Decrease in time to funding } \\
\text { Increase in brand awareness }\end{array}$ \\
\hline $\begin{array}{l}\text { Dyad } \\
\text { Co-Location } \\
\text { Org. }\end{array}$ & $\begin{array}{l}\text { \# connected startups } \\
\text { \# university researchers } \\
\text { \# visitors } \\
\text { \# meet ups/seminars/conferences } \\
\text { \# Corporate R\&D personnel involved } \\
\text { X\% utility of offered equipment } \\
\text { \# startups scaling to X countries }\end{array}$ & $\begin{array}{l}\text { \# startups per week } \\
\text { \# university researchers per month } \\
\text { \# visitors per month } \\
\text { \# meet ups/seminars/ } \\
\text { Conferences per month } \\
\text { \# corporate R\&D personnel involved } \\
\text { \% utility of equipment per week } \\
\text { \# startups scaling to X countries annually }\end{array}$ & $\begin{array}{l}\text { Final \# connected startups } \\
\text { Final \# university researchers } \\
\text { Final \# visitors } \\
\text { Total \# meet ups/seminars/conferences } \\
\text { Total Corporate R\&D personnel involved } \\
\text { Final percentage utility of offered equipment } \\
\text { Total \# startups scaling to X countries }\end{array}$ \\
\hline Government & $\begin{array}{l}\mathrm{X} \% \text { connected startups to the co-location unit } \\
\mathrm{Y} \% \text { of connected startups scale to X countries } \\
\mathrm{Z} \% \text { of digital innovation ideas transferred from } \\
\text { startups to the corporation } \\
\text { \# of New firms established in the region }\end{array}$ & $\begin{array}{l}\text { \# startups involved annually } \\
\text { \# of connected startups that have scaled to X } \\
\text { countries annually } \\
\text { \# of digital innovation ideas transferred from } \\
\text { startups to the corporation annually } \\
\text { \# of New firms established in the region annually }\end{array}$ & $\begin{array}{l}\text { Total \# connected startups } \\
\text { Total \# connected startups that scaled to } \\
\text { X countries } \\
\text { Total \# of digital innovation ideas transfe- } \\
\text { rred from startups to the corporation } \\
\text { Total \# of New firms established in the region }\end{array}$ \\
\hline
\end{tabular}




\section{Conclusions \& Implications}

The main goal of this paper was, by analyzing relevant articles on the phenomenon 'business co-location' in management literature, to extend existing knowledge on this concept and to identify a framework and potential metrics for measuring and evaluating the results of the model: corporate-startup co-location. As could be found from the literature review the phenomenon of business co-location has been used primarily in knowledge intensive industries in which collaboration with external partners might be the only way to manage systemic technologies and innovation. The very foundation behind the establishment of many of these co-location spaces seem to be a 'belief', which also have been proven in research, that geographical proximity does matter for an increasingly effective knowledge dissemination, specifically in the case of tacit knowledge that usually is important for new innovations. Geographical proximity was also shown to be important for the corporation to more efficiently, and with less transaction costs, create 'wide ties' that could connect the corporation into new areas of knowledge (e.g. a Pharma company that access new knowledge in digital technologies). However, even if this geographical proximity might benefit the corporation and the government by strengthen the local ecosystem, the startup might later in its growth, need to be connected to a global ecosystem or network in which organizational proximity might be more important than geographical. In addition, while most models for corporate-startup collaboration build on some type of formal contract between the corporation and the startup, co-location is usually characterized by more informal ties and the only formal contract might be for renting a space in the co-location area. This means that it is harder to require or even expect more 'hard core KPIs' in the case of co-location, compared to e.g. corporate acceleration or corporate venturing. Here more research would be needed on how to evaluate and drive progress in a context of mostly informal ties. Maybe one potential research area to look into would be the area of 'open source' and what could be learned from this phenomenon. Further, from a government perspective, co-location initiatives are usually funded as the belief is that this is good for the startups and for the nation/industry sector. However, in the literature review it was rather clear that also the corporates both need to and do benefit from this kind of initiative. One interesting area for future research is how IP in the form of tacit knowledge actually transfer from the engaged startups to the corporation and therefore benefit the corporation from an innovation perspective.

Finally, in regard to framework and areas of metrics, as could be found from the literature review, no validated framework or areas of metrics seem to exist for evaluating the results from co-location initiatives. However, synthesizing the findings from the new literature review, dimensions of a multi-stakeholder framework and areas of metrics, relevant for different stakeholders, do emerge and were presented above.

The implication for researchers is that the presented framework and areas of metrics should be viewed as a first 'prototype' and needs further refinement through testing and validation. The implication for business managers is similar to that for researchers. They now have a framework and areas of metrics that they could start testing and refine in order to make it fit with their local objectives and conditions.

\section{References}

Autio, E., Nambisan, S., Thomas, LDW, and Wright, M. (2018). Digital affordances, spatial affordances, and the genesis of entrepreneurial ecosystems. Strategic Entrepreneurship Journal, 12(1), pp. 72-95.

Badescu, M. and Garcés-Ayerbe, C. (2009). The impact of information technologies on firm productivity: Empirical evidence from Spain. Technovation, Vol. 29, No.2, pp. 122-129.

Bamford, J. and Ernst, D. (2002). Managing an alliance portfolio. The McKinsey Quarterly 3, pp. 29-39.

Bouncken, R.B., Clauss, T. and Reuschl, A.J. (2016). Coworking-spaces in Asia: A Business Model Design Perspective. Paper presented at SMS Special Conference, Hong Kong, China.

Cabral, V., and van Winden, W. (2016). Coworking: an analysis of coworking strategies for interaction and innovation. International Journal of Knowledge-Based Development, Vol. 7, No. 4, pp. 357377.

Cabral, V. and van Winden, W. (2018). The promise of coworking environments: a content analysis of the positioning of collaborative workspaces in Amsterdam. Centre for Applied Research on Economics \& Management, Amsterdam University of Applied Sciences, Amsterdam, Netherlands.

Clauss, T. and Spieth, P. (2017). Governance of open innovation networks with national vs international scope. Journal of Strategy and Management, Vol. 10, No. 1, pp. 66-85.

Chesbrough, H. (2003). "Open innovation: The new imperative for creating and profiting from technology”, Boston, MA: Harvard Business School Press.

Chesbrough, H. and Rosenbloom, R. (2002). The role of the business model in capturing value from innovation: evidence from Xerox Corporation's technology spin-off companies. Industrial and Corporate Change, Vol. 11, No. 3, pp. 529-555.

Christensen, C.M. and Overdorf, M. (2000). "Meeting the challenge of disruptive change”, Harvard Business Review, Vol. 78, No. 2, pp. 66-76.

Chow, W. and Chan, L.S. (2008). Social network, social trust and shared goals in organizational knowledge sharing. Information \& Management, Vol. 45, pp. 458-465.

Cooke, P. (2002). Biotechnology Clusters as Regional, Sectoral Innovation Systems. International Regional Science Review, Vol. 25, No. 1, pp. 8-37.

Drori, I. and Wright, M. (2018), Accelerators: characteristics, trends and the new entrepreneurial ecosystem, chapter 1 in Wright \& Drori eds. (2018), pp. 1-20. 
Frow, P., Nenonen, S., Payne, A. and Storbacka, K. (2015). Managing Co-creation Design: A Strategic Approach to Innovation. British Journal of Management, pp. 1-21.

Gallini, N. T. (2002). The Economics of Patents: Lessons from Recent U.S. Patent Reform. Journal of Economic Perspectives, Vol. 16, No. 2, pp. 131-154.

Gallivan, M (2008). Striking a balance between trust and control in a virtual organization: A content analysis of open source software case studies. Information Systems Journal, Vol. 11, No. 4, pp. 277-304.

Gertler, M.S. and Levitte, Y.M. (2005). Local Nodes in Global Networks: The Geography of Knowledge Flows in Biotechnology Innovation. Industry and Innovation, Vol. 12, No. 4, pp. 487-507

Hess, T., Matt, C., Benlian, A. and Wiesböck, F. (2016). Options for Formulating a Digital Transformation Strategy. MIS Quarterly Executive, Vol. 15, No. 2, pp. 123-139.

Hochberg, Y.V. (2016). Accelerating Entrepreneurs and Ecosystems: The Seed Accelerator Model. Innovation Policy and the Economy, Vol. 16, No. 1, pp. 25-51.

Holste, J.S. and Fields, D. (2010). Trust and tacit knowledge sharing and use. Journal of Knowledge Management, Vol. 14 No. 1, pp. 128-140.

Inkpen, A.C. and Tsang, E.W.K (2005). Social capital, networks, and knowledge transfer. Academy of Management Review, Vol. 30, No. 1, pp. 146-165.

Irving, G.L., Ayoko, O.B. and Ashkanasy, N.M. (2019). Collaboration, Physical Proximity and Serendipitous Encounters: Avoiding collaboration in a collaborative building. Organization Studies, pp. 1-24

Kilubi, I. (2016). Strategic technology partnering capabilities. Journal of Strategy and Management, Vol. 9, No. 2, pp. 216-255.

Lee, S.M., Olson, D.L. and Trimi, S. (2012). Co-innovation: convergenomics, collaboration, and co-creation for organizational values. Management Decision, Vol. 50, No. 5, pp. 817-831.

Lemarié, S., Mangematin, V., and Torre, A. (2001). Is the Creation and Development of Biotech SMEs Localised? Conclusions Drawn from the French Case. Small Business Economics, Vol. 17, No. 1/2, pp. 61-76.

March, J.G. (1991) Exploration and exploitation in organizational learning. Organization Science, Vol. 2, pp:71-87.

Matt, C., Hess, T. and Benlian, A. (2015). Digital Transformation Strategies. Business \& Information Systems Engineering, Vol. 57, No. 5, pp. 339-343.

McKelvey, M, Alm, H., and Riccaboni, M. (2003). Does co-location matter for formal knowledge collaboration in the Swedish biotechnology-pharmaceutical sector? Research policy, Vol. 32, No. 3, pp. 483-501.
Muegge, S. 2013. Platforms, Communities, and Business Ecosystems: Lessons Learned about Technology Entrepreneurship in an Interconnected World. Technology Innovation Management Review, Vol. 3, No. 2, pp. 5-15.

Nagy, G. and Lindsay, G. (2018). Why Companies Are Creating Their Own Coworking Spaces. Harvard Business Review online, accessed 15 April 2020.

Nambisan, S. (2017). Digital entrepreneurship: Toward a digital technology perspective of entrepreneurship. Entrepreneurship Theory and Practice, Vol. 41, No. 6, pp. 1029-1055.

Nonaka, I. (1994). A dynamic theory of organizational knowledge creation. Organization Science, Vol. 5, No. 1, pp. 14-37.

Oukil, M. S. (2011). A development perspective of technology-based entrepreneurship in the Middle East and North Africa. Annals of Innovation \& Entrepreneurship, Vol. 2, No. 1, pp. 1-13.

Porter, K., Whittington, KB., and Powell, W. (2006). The institutional embeddedness of high-tech regions: Relational foundations of the Boston biotechnology community. In Stefano Breschi and Franco Malerba, eds., Clusters, Networks, and Innovation, Oxford: Oxford University Press.

Powers, T. and Wilson, R. (2010). Management perspectives of high technology strategic alliance outcomes. Journal of Strategy and Management, Vol. 3, No. 1, pp. 4-19.

Robinson, D, Rip, A., and Mangematin, V. (2007). Technological Agglomeration and the emergence of clusters and networks in nanotechnology. Research Policy, Vol. 36, No. 6, pp. 871-879.

Romero, D. and Molina, A. (2011). Collaborative networked organisations and customer communities: value co-creation and co-innovation in the networking era. Production Planning \&amp; Control, Vol. 22, No. 5-6, pp. 447-472

Roth, A., Dumbach, M., Schliffka, B. and Möslein, K. (2017). Successful management of diverse corporate innovation communities. Journal of Strategy and Management, Vol. 10, No. 1, pp. 2-18.

Rothwell, R and Dodgson, M. (1991). External linkages and innovation in small and medium-sized enterprises. R\&D Management, Vol. 21, No. 2, pp. 125-138.

Simard, C. and West, J. (2005), Knowledge Networks and the geographic locus of innovation (chapter 11), submitted for Chesbrough et al. (2006), Open innovation: Researching a New Paradigm, Oxford University Press, Oxford, UK

Siota, J., Alunni, A., Riveros-Chacón, P., Wilson, M. and Karlsson Dinnetz, M. (2020). Corporate Venturing: Insights for European Leaders in Government, University and Industry. EUR 30060 EN, Publications Office of the European Union. Luxembourg. 
Song, M., Berends, H., Van Der Bij, H., and Weggeman, M. (2007). The effect of IT and co-location on knowledge dissemination, The Journal of product innovation management, Vol. 24, No. 1, pp. 52-68. Steiber, A., Alänge, S., and Corvello, V. (2020a). Measuring performance in corporate-startup co-creation: a review of the literature, submitted to International Journal of Innovation Management.

Steiber, A and Alänge, S (2020). Corporate-Startup Co-Creation for Increased Innovation and Societal Change. Triple Helix Journal, pp. 1-23.

Stuart, T. and Sorenson, O. (2003). The geography of opportunity: Spatial heterogeneity in founding rates and the performance of biotechnology firms, Research Policy, Vol. 32, No. 2, pp. 229- 253.

Teece, D. (1986). Profiting from technological innovation: Implications for integration, collaboration, licensing and public policy, Research Policy, Vol. 15, No. 6, pp. 285-305

Teece, D., (1986a). Transaction cost economics and the multinational enterprise, Journal of Economic Behavior and Organization, Vol. 7, pp. $21-45$

Teece, D., (1989). Interorganizational requirements of the innovation process. Managerial and Decision Economics, Vol. 10, No. 1, pp. 35-42.

Trabucchi, D., Buganza, T. and Pellizzoni, E. (2017). Give away your digital services: Leveraging big data to capture value. Research-Technology Management, Vol. 60, No. 2, pp. 43-52.
Valkokari, K., Seppänen, M., Mäntylä, M., and Jylhä-Ollila, S. (2017). Orchestrating Innovation Ecosystems: A Qualitative Analysis of Ecosystem Positioning Strategies. Technology Innovation Management Review, Vol. 7, No. 3, pp. 12-24.

Vanhaverbeke, W. (2005). The Inter-organizational context of Open innovation (chapter 10), submitted for Chesbrough et al. (2006). Open innovation: Researching a New Paradigm, Oxford University Press, Oxford, UK

Webster, J. and Watson, R. (2002). Analyzing the Past to Prepare for the Future: Writing a Literature Review. MIS Quarterly, Vol. 26, No. 2, pp. xiii-xxiii

Weiblen, T. and Chesbrough, H. (2015). "Engaging with startups to enhance corporate innovation". California Management Review, Vol. 57, No. 2, pp. 66-90.

Yeung, H.W-C., Liu, W. and Dicken, P. (2006). Transnational Corporations and Network Effects of a local manufacturing cluster in mobile telecommunications equipment in China. World Development, Vol. 34, No. 3, pp. 520-541.

Zenun M.M.N., Loureiro G., and Araujo C.S. (2007). The Effects of Teams' Co-location on Project Performance. In: Loureiro G., Curran R. (eds) Complex Systems Concurrent Engineering. Springer, London. 
